Rev. Bras. Saúde Prod. Anim., Salvador, v.15, n.3, p.740-753 jul./set., 2014 http://www.rbspa.ufba.br

\title{
Composição química da carne de cordeiros abatidos com diferentes espessuras de gordura subcutânea
}

\author{
Chemical composition of meat from lambs slaughtered with different fat thicknesses
}

\author{
SENEGALHE, Franciane Barbiéri Dias ${ }^{1 *}$; MACEDO, Francisco de Assis Fonseca ${ }^{2}$; \\ MORA, Natália Holtz Alves Pedroso ${ }^{3}$; GUALDA, Thiago Peres ${ }^{3}$; RADIS, Ana \\ Cláudia $^{3}$; QUEIROZ, Edicarlos Oliveira ${ }^{3}$; MACEDO, Filipe Gomes ${ }^{3}$
}

\footnotetext{
${ }^{1}$ Universidade Estadual de Maringá, Departamento de Zootecnia, Maringá, Paraná, Brasil.

${ }^{2}$ Universidade Federal de Sergipe, Departamento de Zootecnia, Aracaju, Sergipe, Brasil.

${ }^{3}$ Universidade Estadual de Maringá, Programa de Pós-Graduação em Zootecnia, Maringá, Paraná, Brasil.

*Endereço para correspondência: francibardi_08@hotmail.com
}

\section{RESUMO}

Foram utilizados trinta e quatro cordeiros machos não castrados, sendo 16 Santa Inês (SI) e 18 1/2 Dorper $+1 / 2$ Santa Inês $(1 / 2 \mathrm{D}+1 / 2 \mathrm{SI})$. Os animais foram abatidos com 2,0; 3,0 e 4,0mm de espessuras de gordura subcutânea, para verificar o efeito do grupo genético e espessura de gordura ao abate na composição química da carne de cordeiros. Os cordeiros foram confinados, recebendo ração completa peletizada, calculada para ganho médio diário de $0,30 \mathrm{~kg}$. Foram realizadas avaliações por ultrassonografia na região do lombo entre a $12^{\mathrm{a}}$ e $13^{\mathrm{a}}$ costelas. Para os teores de lipídeos totais da carne foram observadas diferenças entre o grupo genético (SI: $4,78 \mathrm{~g} / 100 \mathrm{~g}$; $1 / 2$ D+ $1 / 2$ SI: 6,45g/100g) e as espessuras de gordura ao abate $(2,0 \mathrm{~mm}$ : $4,77 \mathrm{~g} / 100 \mathrm{~g} ; 3,0 \mathrm{~mm}$ : $5,20 \mathrm{~g} / 100 \mathrm{~g}$ e 4,0mm: 6,86g/100g). Foram observadas diferenças para o teor de ácidos graxos saturados nas diferentes espessuras ao abate (2,0mm: 26,52g/100g; 3,0mm: 27,07g/100g e 4,0mm: 24,63g/100g). Constatou-se a presença de um isômero de ácido linoleico conjugado, C18:1n 9 cis ,11trans. Analisando-se a concentração total dos ácidos graxos insaturados, observou-se que diferentes espessuras de gordura influenciaram significativamente as concentrações dos ácidos graxos poliinsaturados (2,0mm: $8,36 \mathrm{~g} / 100 \mathrm{~g}$; 3,0mm: $8,54 \mathrm{~g} / 100 \mathrm{~g}$ e $4,0 \mathrm{~mm}: 11,18 \mathrm{~g} / 100 \mathrm{~g}$ ). A carne de cordeiros demonstrou ser altamente benéfica no teor lipídico e de um isômero de Ácido Linoleico Conjugado. Nas condições de realização do experimento a carne de cordeiros com 4,0mm de espessura de gordura subcutânea demonstraram melhor incremento de ácidos graxos poli-insaturados em relação aos demais, melhorando assim a qualidade nutricional da carne tornando-a mais adequada para a alimentação humana.

Palavras-chave: ácidos graxos insaturados, CLA, lipídeos, ovinos

\section{SUMMARY}

Thirty-four not castrated lambs, 16 Santa Ines (SI) and 18 1/2 Dorper $+1 / 2$ Santa Ines $(1 / 2 \mathrm{D}+1 / 2 \mathrm{SI})$, were slaughtered with different subcutaneous fat thicknesses to verify the effect of genotype and fat thickness on chemical composition of the meat. The lambs remained confined, from weaning to slaughter, and they were fed with complete pelleted ration calculated for daily weight gain of $0.3 \mathrm{~kg}$. Ultrasound evaluations were performed between the 12th and 13th ribs in the loin area. The slaughter was carried out when the lambs reached the thickness of fat pre-determined: 2.0, 3.0 and $4.0 \mathrm{~mm}$. There were differences in the total lipids of the meat between the genetic groups (SI: $4.78 \mathrm{~g} / 100 \mathrm{~g} ; 1 / 2$ D $1 / 2$ + SI: $6.45 \mathrm{~g} / 100 \mathrm{~g}$ ) and fat thickness at slaughter (2.0mm: $4.77 \mathrm{~g} / 100 \mathrm{~g}$; 3.0mm: $5.20 \mathrm{~g} / 100 \mathrm{~g}$ and $4.0 \mathrm{~mm}: 6.86 \mathrm{~g} / 100 \mathrm{~g}$ ). The contents of fatty acids differed in the different fat thicknesses at slaughter $(2.0 \mathrm{~mm}: 26.52 \mathrm{~g} / 100 \mathrm{~g}$; 3.0mm: $27.07 \mathrm{~g} / 100 \mathrm{~g}$ e $4.0 \mathrm{~mm}: 24.63 \mathrm{~g} / 100 \mathrm{~g}$ ). It was observed the presence of an isomer of Conjugated Linoleic Acid, C18: 1n 9cis, 11trans. Analyzing the total concentration of unsaturated fatty acids, it was observed that the different thicknesses of fat signifycantly affected the 
concentration of polyunsaturated fatty acids (2.0mm: $8.36 \mathrm{~g} / 100 \mathrm{~g} ; \quad 3.0 \mathrm{~mm}: \quad 8.54 \mathrm{~g} / 100 \mathrm{~g}$ e 4.0mm: $11.18 \mathrm{~g} / 100 \mathrm{~g}$ ). Meat from lambs proved highly beneficial in lipid content and an isomer of CLA. Under the conditions of the experiment the lamb meat slaughtered with $4.0 \mathrm{~mm}$ thickness of subcutaneous fat showed better increase of polyunsaturated fatty acids in relation to the other, thus improving the nutritional quality of the meat making it more suitable for human consumption.

Keywords: CLA, lipids, sheep, unsaturated fatty acid

\section{INTRODUÇÃO}

A exigência do consumidor direciona a produção de alimentos para a qualidade nutricional. A carne ovina surge, então, neste cenário, como alternativa para que sejam atendidos os anseios dos consumidores cada vez mais preocupados com a saúde. Carnes de melhor qualidade nutricional e sensorial passaram a ser preferência, mais saudáveis e, em alguns casos, com propriedades funcionais benéficas à saúde humana (COSTA et al., 2008).

Os lipídios oriundos da alimentação aumentam a capacidade de absorção de vitaminas lipossolúveis, fornecem ácidos graxos essenciais importantes para as membranas dos tecidos e atuam como precursores da regulação do metabolismo. Estes ácidos sofrem um processo de bio-hidrogenação, os quais são convertidos em saturados, apresentando menor toxidez, favorecendo o aumento da deposição desses ácidos graxos poli-insaturados no músculo, melhorando, portanto, a qualidade nutricional e funcional da carne (PONNAMPALAM et al., 2001).

As propriedades químicas dos lipídeos alteram diretamente as qualidades nutricionais, sensoriais e de conservação da carne (HASHIMOTO, et al., 2007).
Durante o crescimento do animal, a deposição de gordura, além de variar em quantidade, varia em sua distribuição nos diferentes depósitos, a partição da deposição de gordura nos diferentes depósitos corporais segue ordem cronológica fixa sendo a gordura perirrenal a primeira a ser depositada, seguida pela intermuscular, subcutânea e, finalmente, pela intramuscular (SAINZ \& HASTING, 2000).

$\mathrm{O}$ abate com diferentes espessuras de gordura subcutânea, considerando-se o grupo genético, poderá proporcionar carcaças de melhor grau de acabamento, ao mesmo tempo em que a gordura tem a finalidade desejável de manter a palatabilidade e aumentar a maciez, seu excesso pode ser prejudicial à saúde (STRYDOM et al., 2009).

Assim, objetivou-se avaliar o efeito do grupo genético e espessuras de gordura subcutânea ao abate sobre a composição química e o perfil de ácidos graxos de cordeiros Santa Inês e $1 / 2$ Dorper + Santa Inês, abatidos com 2,0; 3,0 e 4,0mm de espessura de gordura subcutânea, avaliados por ultrassonografia, terminados em confinamento.

\section{MATERIAL E MÉTODOS}

O experimento foi realizado na Universidade Estadual de Maringá no setor de confinamento de ovinos. Foram utilizados 34 cordeiros machos não castrados, recém-desmamados, com aproximadamente 60 dias de idade e com peso médio de $21,56 \pm 1,34 \mathrm{~kg}$, sendo 18 do grupo genético $1 / 2$ Dorper + $1 / 2$ Santa Inês e 16 Santa Inês. Os animais abatidos por espessura de gordura subcutânea foram 11 com $2,0 \mathrm{~mm} ; 12 \mathrm{com} 3,0 \mathrm{~mm}$ e $11 \mathrm{com}$ $4,0 \mathrm{~mm}$. Os animais foram distribuídos aleatoriamente, em baias individuais 
cobertas com piso ripado suspenso, sendo os tratamentos definidos como espessuras de gordura subcutânea entre a $12^{\mathrm{a}}$ e $13^{\mathrm{a}}$ costelas, em 2,0; 3,0 e $4,0 \mathrm{~mm}$, avaliados por ultrassonografia. Os cordeiros foram alimentados com ração total misturada e peletizada, formulada para um ganho de peso diário de 0,30kg (NRC, 2007). A composição química da ração fornecida aos cordeiros foi analisada no Laboratório de Nutrição e Alimentação Animal, pertencente ao Departamento de Zootecnia da Universidade Estadual de Maringá (Tabela 1).

Tabela 1. Composição percentual dos ingredientes, química e bromatológica da ração experimental

\begin{tabular}{|c|c|}
\hline Item & Composição \\
\hline Feno de Estilosantes Campo & 20,00 \\
\hline Milho moído grosso & 51,83 \\
\hline Farelo de Soja & 17,01 \\
\hline Casca de Soja & 5,00 \\
\hline Melaço & 2,00 \\
\hline Cloreto de Amônia & 2,00 \\
\hline Bicarbonato de Sódio & 1,00 \\
\hline Mistura Mineral $^{1}$ & 1,00 \\
\hline Matéria Seca & 87,80 \\
\hline Proteína Bruta & 16,12 \\
\hline Extrato Etéreo & 2,68 \\
\hline Ácidos Graxos Saturados & 20,45 \\
\hline Ácidos Graxos & 39,97 \\
\hline Ácidos Graxos Poli- & 39,58 \\
\hline Fibra em Detergente Neutro & 28,67 \\
\hline Fibra em Detergente Ácido & 14,85 \\
\hline Cinzas & 7,48 \\
\hline Cálcio & 0,49 \\
\hline Fósforo & 0,37 \\
\hline Digestibilidade in vitro da & 77,15 \\
\hline Nutrientes digestíveis totais & 76,60 \\
\hline $\begin{array}{l}{ }^{1} \text { Níveis de garantia do su } \\
\text { por kg: Cálcio } 220 \mathrm{~g} \text {, Fósfor } \\
25,5 \mathrm{~g} \text {, Enxofre 24g, } \\
\text { Manganês } 1500 \mathrm{mg} \text {, Zincc } \\
1200 \mathrm{mg} \text {, Cobalto 280mg } \\
\text { Selênio 30mg e Flúor } 300 \mathrm{~m} \\
\text { pela equação (Undersand } \\
\% \text { NDT }=87,84-(0,70 \times \text { FI }\end{array}$ & $\begin{array}{l}\text { mento mineral } \\
30 \mathrm{~g}, \text { Magnésio } \\
\text { rro } 3000 \mathrm{mg} \text {, } \\
\text { 000mg, Cobre } \\
\text { Iodo 260mg, } \\
\text { NDT estimado } \\
\text { et al., 1993): }\end{array}$ \\
\hline
\end{tabular}

As avaliações por ultrassonografia e pesagens foram realizadas a cada 14 dias. Para obtenção da espessura de gordura subcutânea, foi utilizado equipamento de ultrassom, marca HONDA, modelo HS-1500 VET, com transdutor linear multifrequencial de $50 \mathrm{~mm}$ de largura, utilizando frequência de 7,5 MHz.

As mensurações foram realizadas pelo mesmo técnico, do lado esquerdo, entre a $12^{\mathrm{a}}$ e $13^{\mathrm{a}}$ costelas, a $4 \mathrm{~cm}$ da coluna vertebral. A pressão na probe foi mantida mínima para evitar a compressão da gordura. Depois de capturada a imagem, a espessura da gordura subcutânea neste ponto foi medida usando-se o ponteiro eletrônico do ultrassom.

Conforme os cordeiros atingiam a espessura de gordura pré-determinada de 2,$0 ; 3,0$ e 4,0mm na avaliação por ultrassonografia eram abatidos no dia seguinte às aferições, independentemente do peso. As médias para peso corporal e idade ao abate foram de $37,20 \mathrm{~kg}$ e 124 dias para o grupo genético Santa Inês; $38,22 \mathrm{~kg}$ e 122 dias para $1 / 2$ Dorper $+1 / 2$ Santa Inês. Para as espessuras de gordura subcutânea foram 33,74kg e 108 dias para os cordeiros abatidos com 2,0mm; $37,79 \mathrm{~kg}$ e 119 dias para $3,0 \mathrm{~mm}$; $41,60 \mathrm{~kg}$ e 146 dias para os abatidos com 4,0mm.

Após $18 \mathrm{~h}$ em jejum de sólidos, os animais foram insensibilizados por meio de eletronarcose de $220 \mathrm{~V}$ por 8 segundos. Em seguida foram realizadas as sangrias e as eviscerações, sendo as carcaças pesadas e armazenadas em câmara frigorífica a $4^{\circ} \mathrm{C}$ por $24 \mathrm{~h}$.

As carcaças resfriadas foram pesadas e divididas longitudinalmente, do lado esquerdo foi retirado o músculo Longissimus dorsi e entre a $6^{\mathrm{a}}$ e $10^{\mathrm{a}}$ vértebra torácica, que foram utilizados para análises químicas. Foram 
determinados os teores de umidade, cinzas e proteína, segundo metodologia da AOAC (2000). Para ácidos graxos a extração de lipídios totais foi feita utilizando-se a técnica a frio descrita por Folch et al. (1957). Para a transesterificação dos triacilgliceróis foi utilizado o método 5509 da ISO (1978). Os ésteres de ácidos graxos foram isolados e analisados através do cromatógrafo gasoso Shimadzu 14A.

As análises estatísticas foram realizadas utilizando-se o programa SAS (SAS INSTITUTE, 2002), considerando-se os grupos genéticos (Santa Inês e $1 / 2$ Dorper $+1 / 2$ Santa Inês), as diferentes espessuras de gordura subcutânea ao abate $(2,0 ; 3,0$ e 4,0 mm), e a interação entre estes. As médias foram comparadas pelo teste de Tukey com $5 \%$ de significância. As correlações foram realizadas por meio de análise de correlações paramétricas de Pearson, utilizando-se as variáveis estudadas, processadas pelo programa SAS com $5 \%$ de significância e comparadas pelo teste de Tukey $(\mathrm{P}<0.05)$.

\section{RESULTADOS E DISCUSSÃO}

Não houve efeito de interação entre grupo genético e espessura de gordura subcutânea ao abate. Sendo assim, os resultados serão discutidos como efeitos principais.

Não foi verificado efeito do grupo genético e da espessura de gordura subcutânea sobre os teores de matéria seca, cinzas e proteína bruta da carne (Tabela 2). Observou-se que os cordeiros Santa Inês produziram carne com menor teor de lipídeos totais do que os $1 / 2$ Dorper $+1 / 2$ Santa Inês. Os teores de lipídeos totais aumentaram com as espessuras de gordura subcutânea ao abate independente do grupamento genético.

Segundo Sañudo et al. (2000b), existem fatores que influenciam na composição química da carne, tais como: genótipo, estado fisiológico, dieta, sistema de manejo e tipo de músculo.

Tabela 2. Médias e desvios-padrão da composição química na carne de cordeiros Santa Inês e $1 / 2$ Dorper $+1 / 2$ Santa Inês, abatidos com diferentes espessuras de gordura subcutânea

\begin{tabular}{lccccc}
\hline \multirow{2}{*}{ Item } & \multicolumn{2}{c}{ GRUPO GENÉTICO } & \multicolumn{2}{c}{ ESPESSURA DE GORDURA } \\
\cline { 2 - 5 } & SI & $1 / 2 \mathrm{D}+1 / 2 \mathrm{SI}$ & $2,0 \mathrm{~mm}$ & $3,0 \mathrm{~mm}$ & $4,0 \mathrm{~mm}$ \\
\hline Umidade $(\mathrm{g} / 100 \mathrm{~g})$ & $71,51 \pm 1,03^{1}$ & $69,82 \pm 1,09$ & $71,31 \pm 1,32$ & $71,13 \pm 1,26$ & $70,84 \pm 1,29$ \\
Cinza $(\mathrm{g} / 100 \mathrm{~g})$ & $1,04 \pm 0,42$ & $1,03 \pm 0,51$ & $1,06 \pm 0,83$ & $1,09 \pm 0,74$ & $1,01 \pm 0,91$ \\
ProteinaBruta $(\mathrm{g} / 100 \mathrm{~g})$ & $22,62 \pm 0,33$ & $22,72 \pm 0,31$ & $22,86 \pm 0,40$ & $22,58 \pm 0,38$ & $22,58 \pm 0,41$ \\
LipídeosTotais $(\mathrm{g} / 100 \mathrm{~g})$ & $4,78 \pm 0,41 \mathrm{~b}$ & $6,45 \pm 0,44^{\mathrm{a}}$ & $4,77 \pm 0,53 \mathrm{~b}$ & $5,20 \pm 0,50 \mathrm{ab}$ & $6,86 \pm 0,53^{\mathrm{a}}$ \\
\hline
\end{tabular}

Médias seguidas de letras iguais, nas linhas, indicam que não houve diferença pelo teste de Tukey $(\mathrm{P}>0,05)$. $\mathrm{SI}=$ Santa Inês; $1 / 2 \mathrm{D}+1 / 2 \mathrm{SI}=1 / 2$ Dorper $+1 / 2$ Santa Inês.

Segundo Tornberg et al. (2005) a composição química da carne apresenta valores médios de $75 \%$ de umidade, $20 \%$ de proteína e $3 \%$ de gordura e $2 \%$ de substâncias solúveis não proteicas.
No presente trabalho, nota-se que os valores de umidade e lipídeos totais discordam dos valores citados por Tornberg et al. (2005) apresentando 
valores médios de 70,87\% para umidade e 5,6\% para os lipídeos totais.

$\mathrm{O}$ alto teor de lipídeos totais na carne pode influenciar negativamente o produto carne, já que os consumidores apresentam certa restrição à gordura de ruminantes principalmente a ovina, isto se deve ao fato do alto teor de ácidos graxos saturados (OSÓRIO \& OSÓRIO 2003).

$\mathrm{O}$ aumento na gordura corporal $\mathrm{e}$ subcutânea tende a alterar os componentes químicos da carne, à medida que houve o aumento nas espessuras de gordura subcutânea e como consequência o incremento no peso corporal, os valores dos componentes químicos aumentaram em valores absolutos, porém quando analisados em valores relativos, não se observa o mesmo comportamento, pois a proporção de proteína e cinzas permanece constante, enquanto que a de gordura aumenta e a de água diminui (OSÓRIO et al., 2002)

As diferenças encontradas (Tabela 2) para o grupo genético estão de acordo com Oliván et al. (2000) dentro de cada espécie, e sempre que os animais submetidos as mesmas condições de manejo e alimentação , o grupo genético influenciará notavelmente sobre o conteúdo de lipídeos totais. Rosanova et al. (2005) corroboram a respeito da raça Dorper em relação à precocidade de terminação, característica responsável pela rápida deposição de gordura na carcaça, principalmente quando os animais são terminados em confinamento. Por outro lado, Madruga et al. (2006) ao avaliarem o efeito do genótipo e do sexo sobre a composição química e o perfil de ácidos graxos da carne de cordeiros, não observaram diferenças entre os grupos genéticos Santa Inês e 1/2 Dorper $+1 / 2$ Santa Inês.

Já Moreno et al. (2011) relataram que o teor de gordura da carne seja influenciado pelo grupo genético, enquanto umidade, proteína e minerais são pouco influenciados pelo grupo genético, justificando os resultados observados neste trabalho.

As diferenças encontradas nos teores de lipídeos totais nas distintas espessuras de gordura ao abate $(2,0 ; 3,0$ e 4,0mm) podem influenciar a aceitabilidade das carnes. Para Sañudo et al. (2000a) menor quantidade de gordura reduz consideravelmente a aceitabilidade da carne de cordeiros, relatando que carnes menor teor de gordura foram classificadas em teste sensorial como inferiores em sabor e satisfação e que a qualidade sensorial tanto de odor e de "flavor" está correlacionada positivamente ao conteúdo de C18:0 e C18:3. Porém, por outro lado, o excesso de lipídios pode diminuir a apreciação do produto.

$\mathrm{O}$ fato de a carne ser fonte de gordura na dieta principalmente de ácidos graxos saturados faz com que se aumente o interesse na manipulação da composição de ácidos graxos na carne, Wood et al. (2003) determina que a razão recomendada de ácidos graxos poliinsaturados ácidos graxos saturados (P: S) deve ser aumentado para acima de 0,4 .

$\mathrm{Na}$ carne de cordeiros Santa Inês e 1/2 Dorper $+1 / 2$ Santa Inês, abatidos com diferentes espessuras de gordura subcutânea (Tabela 3) foram identificados 24 ácidos graxos, sendo sete saturados; sete monoinsaturados e dez poliinsaturados. Resultados semelhantes foram encontrados por Maia et al. (2012) ao avaliarem o efeito do genótipo sobre a composição química e o perfil de ácidos graxos da carne de borregas identificaram 27 ácidos graxos, sendo nove ácidos graxos saturados, oito monoinsaturados e dez poli-insaturados.

O maior teor de ácidos graxos poliinsaturados presente na carne de cordeiros está associado diretamente à importância que exerce no metabolismo humano, sabe-se que existem dois grupos 
Rev. Bras. Saúde Prod. Anim., Salvador, v.15, n.3, p.740-753 jul./set., 2014 http://www.rbspa.ufba.br ISSN 15199940

principais de gorduras poli-insaturadas: omega-3 (n-3) e omega-6 (n-6), considerados "essenciais" já que o ser humano não consegue sintetizá-los em seu organismo as outras gorduras poli- insaturadas não são consideradas essenciais, pois o organismo humano consegue produzi-las a partir do ácido linolênico e do linoleico (SALDANHA \& GONZALES, 2012).

Tabela 3. Médias e desvios-padrão das áreas dos picos de ácidos graxos da carne de cordeiros Santa Inês e $1 / 2$ Dorper $+1 / 2$ Santa Inês, abatidos com diferentes espessuras de gordura $(\mathrm{g} / 100 \mathrm{~g})$

\begin{tabular}{|c|c|c|c|c|c|c|}
\hline \multirow{2}{*}{ Item } & \multirow{2}{*}{ Nomenclatura } & \multicolumn{2}{|c|}{ Grupo genético } & \multicolumn{3}{|c|}{ Espessuras de Gordura } \\
\hline & & SI & $1 / 2 D+1 / 2$ & $2,0 \mathrm{~mm}$ & $3,0 \mathrm{~mm}$ & $4,0 \mathrm{~mm}$ \\
\hline \multicolumn{7}{|l|}{ Saturados } \\
\hline $\mathrm{C} 8: 0$ & Caprílico & $4,49 \pm 0,62$ & $4,64 \pm 0,60$ & $4,58 \pm 0,81^{\mathrm{a}}$ & $5,80 \pm 0,69^{\mathrm{a}}$ & $3,04 \pm 0,74^{\mathrm{b}}$ \\
\hline C14:0 & Mirístico & $3,70 \pm 0,28$ & $3,71 \pm 0,20$ & $3,77 \pm 0,36$ & $3,55 \pm 0,31$ & $3,84 \pm 0,33$ \\
\hline C16:0 & Palmítico & $2,40 \pm 0,22^{\mathrm{b}}$ & $3,06 \pm 0,21^{\mathrm{a}}$ & $2,81 \pm 0,28$ & $2,79 \pm 0,24$ & $2,83 \pm 0,25$ \\
\hline C18:0 & Esteárico & $13,98 \pm 1,06$ & $14,08 \pm 1,02$ & $14,01 \pm 1,38$ & $13,64 \pm 1,18$ & $13,75 \pm 1,26$ \\
\hline $\mathrm{C} 22: 0$ & Behênico & $0,66 \pm 0,03$ & $0,70 \pm 0,03$ & $0,66 \pm 0,04$ & $0,62 \pm 0,03$ & $0,68 \pm 0,04$ \\
\hline $\mathrm{C} 23: 0$ & Tricosandico & $0,11 \pm 0,04$ & $0,13 \pm 0,04$ & $0,29 \pm 0,06$ & $0,28 \pm 0,05$ & $0,17 \pm 0,06$ \\
\hline $\mathrm{C} 24: 0$ & Lignocérico & $0,11 \pm 0,07$ & $0,50 \pm 0,07$ & $0,40 \pm 0,101$ & $0,39 \pm 0,09$ & $0,32 \pm 0,09$ \\
\hline \multicolumn{7}{|l|}{ Monoinsaturados } \\
\hline $\mathrm{C} 17: 1$ & Heptadecan & $30,64 \pm 1,80$ & $30,57 \pm 1,73$ & $30,93 \pm 2,34$ & $31,05 \pm 2,00$ & $31,98 \pm 2,13$ \\
\hline C16:1 & Palmitoléico & $1,35 \pm 0,21^{\mathrm{b}}$ & $2,13 \pm 0,20^{\mathrm{a}}$ & $2,02 \pm 0,28$ & $1,77 \pm 0,24$ & $1,73 \pm 0,25$ \\
\hline $\mathrm{C} 18: \ln 9 \mathrm{t}$ & Oleico & $30,23 \pm 2,20$ & $31,66 \pm 2,12$ & $31,65 \pm 2,86$ & $31,27 \pm 2,45$ & $30,05 \pm 2,6$ \\
\hline C20:1 & Gadoléico & $0,35 \pm 0,06$ & $0,34 \pm 0,06$ & $0,26 \pm 0,08$ & $0,31 \pm 0,07$ & $0,30 \pm 0,07$ \\
\hline $\mathrm{C} 22: \ln 9$ & Erúcico & $0,09 \pm 0,05$ & $0,05 \pm 0,04$ & $0,06 \pm 0,05$ & $0,05 \pm 0,05$ & $0,07 \pm 0,06$ \\
\hline $\mathrm{C} 24: 1 \mathrm{n}$ & Nervônico & $0,05 \pm 0,01$ & $0,05 \pm 0,01$ & $0,06 \pm 0,01$ & $0,05 \pm 0,01$ & $0,06 \pm 0,01$ \\
\hline \multicolumn{7}{|l|}{ Poli-insaturados } \\
\hline $\mathrm{C} 20: 5 \mathrm{n} 3$ & Timnodônic & $0,36 \pm 0,02$ & $0,02 \pm 0,02$ & $0,02 \pm 0,02^{\mathrm{b}}$ & $0,03 \pm 0,02^{b}$ & $0,622 \pm 0,02^{\mathrm{a}}$ \\
\hline $\mathrm{C} 18: 2 \mathrm{n} 6 \mathrm{t}$ & Linoleico & $3,02 \pm 0,22$ & $3,53 \pm 0,21$ & $3,20 \pm 0,29$ & $3,16 \pm 0,25$ & $3,16 \pm 0,26$ \\
\hline $\mathrm{C} 18: 2 \mathrm{n} 9 \mathrm{c}, 11 \mathrm{t}$ & Rumênico & $1,96 \pm 0,43$ & $2,02 \pm 0,41$ & $1,30 \pm 0,56$ & $1,49 \pm 0,48$ & $1,69 \pm 0,51$ \\
\hline C18:3n6 & Y-linolénico & $2,87 \pm 0,46$ & $3,90 \pm 0,44$ & $3,29 \pm 0,60$ & $3,36 \pm 0,517$ & $3,40 \pm 0,55$ \\
\hline C18:3n3 & Linolênico & $2,41 \pm 0,08$ & $0,15 \pm 0,07$ & $0,13 \pm 0,12$ & $0,14 \pm 0,11$ & $0,34 \pm 0,10$ \\
\hline C20:2 & Eicosadienói & $0,10 \pm 0,05$ & $0,09 \pm 0,05$ & $0,07 \pm 0,07$ & $0,07 \pm 0,06$ & $0,09 \pm 0,06$ \\
\hline $\mathrm{C} 20: 3 \mathrm{n} 6$ & Di-homo- & $0,21 \pm 0,01$ & $0,20 \pm 0,01$ & $0,17 \pm 0,08$ & $0,15 \pm 0,08$ & $0,13 \pm 0,07$ \\
\hline C20:4n6 & Araquidồnic & $0,32 \pm 0,15$ & $0,09 \pm 0,15$ & $0,08 \pm 0,19$ & $0,05 \pm 0,16$ & $0,09 \pm 0,17$ \\
\hline $\mathrm{C} 22: 2$ & Docosadilen & $0,04 \pm 0,02$ & $0,01 \pm 0,02$ & $0,08 \pm 0,02$ & $0,07 \pm 0,02$ & $0,06 \pm 0,02$ \\
\hline $\mathrm{C} 22: 6 \mathrm{n} 3$ & Cervônico & $0,02 \pm 0,01$ & $0,02 \pm 0,01$ & $0,02 \pm 0,01^{\mathrm{b}}$ & $0,02 \pm 0,01^{\mathrm{b}}$ & $1,598 \pm 0,01^{\mathrm{a}}$ \\
\hline Saturados & & $25,45 \pm 1,24$ & $26,82 \pm 1,19$ & $26,52 \pm 1,61^{\mathrm{a}}$ & $27,07 \pm 1,38^{\mathrm{a}}$ & $24,63 \pm 1,47 b$ \\
\hline Monoinsaturados & & $62,71 \pm 1,38$ & $64,80 \pm 1,32$ & $64,98 \pm 1,79$ & $64,41 \pm 1,536$ & $64,19 \pm 1,63$ \\
\hline Poli-insaturados & & $11,31 \pm 1,48$ & $10,03 \pm 1,42$ & $8,36 \pm 1,93^{\mathrm{b}}$ & $8,54 \pm 1,65^{\mathrm{b}}$ & $11,18 \pm 1,76^{\mathrm{a}}$ \\
\hline AGP/AGS & & 0,44 & 0,38 & 0,31 & 0,31 & 0,45 \\
\hline$n-6$ & & 4,42 & 5,72 & 4,74 & 4,72 & 4,78 \\
\hline$n-3$ & & 2,79 & 0,19 & $0,17^{\mathrm{b}}$ & $0,19^{\mathrm{b}}$ & $2,56^{\mathrm{a}}$ \\
\hline
\end{tabular}

Médias seguidas de letras iguais, nas linhas, indicam que não houve diferença pelo teste de Tukey $(\mathrm{P}>0,05)$. AGP/AGS = Ácidos graxos Poli-insaturados: Ácidos Graxos Saturados. 
Entre o total de ácidos graxos identificados, nove ácidos graxos (C18:0; C8:0; C4:0; C16:0; C17:1; C18:1n9, C18:2n9c,11t; C18:2n6t; C18:3n6) constituíram acima de $90 \%$ das áreas totais dos cromatogramas. $\mathrm{O}$ ácido heptadecanóico $\quad(\mathrm{C} 17: 1)$ e oléico (C18:1n9t), somados apresentaram 96\% dos ácidos graxos insaturados totais na carne de cordeiros Santa Inês e 1/2 Dorper + $1 / 2$ Santa Inês abatidos com diferentes espessuras de gordura subcutânea, sendo assim, os que mais contribuíram.

Enquanto que o esteárico (C18:0), contribuiu com 53\% do total dos ácidos graxos saturados. Demonstrando que independente do grupo racial $\mathrm{e}$ da espessura de gordura subcutânea a carne de cordeiros, apresenta melhor perfil lipídico auxiliando assim a ingestão diária de ácidos graxos insaturados.

$\mathrm{O}$ ácido graxo mais abundante encontrado na carne dos animais foi o $\mathrm{C} 18: \ln 9 \mathrm{t}$ (oleico), não diferenciando nos respectivos tratamentos, grupo racial e espessura de gordura subcutânea, essa elevada concentração deve-se o fato de altos teores de ácido esteárico (C18:0) já que o mesmo é o precursor do ácido oleico com o substrato da enzima $\Delta^{9}$ dessaturase (MARTÍN et al., 2006). Por outro lado, o teor do ácido graxo essencial C18:2n6t ( linoleico) foi inferior quando compara do à Scerra et al. (2011) que estudando a composição da gordura intramuscular em cordeiros alimentados com dietas contendo fontes alternativas de proteína observaram média de 12,25 para o ácido linoleico, este dado interfere de maneira negativa já que o ácido linoleico pode ser elongado e dessaturado em ácido araquidônico(LEE \& LIP, 2003)

Os ácidos graxos identificados em maiores proporções na carne de cordeiros dos grupos raciais Santa Inês e 1/2 Dorper $+1 / 2$ Santa Inês abatidos com diferentes espessuras de gordura foram o C16:0, C18:0, C18:1n9t e C17:1. Este resultado encontra-se de acordo com os dados obtidos com cordeiros (MADRUGA et al., 2006; COSTA et al., 2009) isto se deve ao fato de que, nos ruminantes, parte dos ácidos graxos insaturados provenientes da dieta é modificada pelo processo de bio-hidrogenação no ambiente ruminal, como forma de neutralizar o efeito tóxico desses ácidos graxos aos microrganismos ruminais. Como resultado desse processo, a classe dos ácidos graxos saturados é absorvida e incorporada ao tecido muscular (COSTA et al., 2008).

De acordo com Oliveira et. al. (2011) os ácidos graxos saturados encontrados em maior proporção na gordura subcutânea são o palmítico, o mirístico e o esteárico. A carne dos cordeiros $1 / 2$ Dorper $+1 / 2$ Santa Inês apresentou maior teor do ácido graxo C16:0 (palmítico) do que os Santa Inês, corroborando Madruga et al. (2006). Assim, os ácidos graxos de cadeia média presente na gordura animal, tais como o mirístico (C14:0) e palmítico (C16:0), considerados hipercolesterolêmicos podem incrementar tanto a concentração total de colesterol no plasma e elevar os níveis de lipoproteínas de baixa densidade (LDL). Enquanto que os ácidos graxos de maior longitude de cadeia tal como o esteárico (C18:0), considerados neutros quanto ao colesterol plasmático (SCOLLAN et al., 2001; LIMA et al., 2000).

Os ácidos graxos saturados são reconhecidos por aumentarem a concentrações de LDL e colesterol (VALSTA et al., 2005) .Um dos mecanismos propostos para a ação dos ácidos graxos saturados de cadeia média é a redução do número de receptores hepáticos a LDL-Colesterol o que pode diminuir a remoção deste colesterol da corrente sanguínea (COSTA et al., 2006). Foram observadas diferenças para o teor de ácidos graxos saturados nas diferentes espessuras de gordura ao abate $(2,0 ; 3,0 \mathrm{e}$ $4,0 \mathrm{~mm})$. Os animais abatidos com 
espessura de gordura subcutânea de 4,0mm apresentaram menor média no perfil de ácidos graxos saturados quando comparados aos abatidos com 2,0 e 3,0mm. Este dado torna-se de extrema relevância, pois o consumo de carne aumenta o armazenamento de lipídeos intracelular aumentando os riscos de doenças coronarianas e mal de Alzheimer em humanos (BARNARD et al., 2014; MAHENDRAN et al., 2013). Nesse sentido, Costa et al. (2008) indicam que a produção de carnes com níveis adequados de gordura, apresentando menores concentrações de ácidos graxos saturados e colesterol LDL, deve ser priorizada.

Os ácidos graxos monoinsaturados caracterizam-se como de extrema importância pela presença do ácido oleico (C18:1n9t). Em geral, a carne de ruminantes possui maiores concentrações de CLA (Conjugated Linoleic Acid) se comparada à de não ruminantes (SCHMID et al., 2006). Os mesmos autores afirmaram que, entre os ruminantes, a carne ovina contém maior quantidade de CLA $(4,3$ a $19 \mathrm{mg} / \mathrm{g}$ de lipídeo) se comparada à carne bovina $(1,2$ a 10mg/g de lipídeo).

No presente trabalho foi verificado a presença de um isômero de CLA, C18:2n 9 cis ,11trans (ácido rumenico) identificado na carne dos cordeiros Santa Inês e $1 / 2$ Dorper $+1 / 2$ Santa Inês, abatidos com diferentes espessuras de gordura. Funck et al. (2006) estudando os efeitos do CLA e sua relação com a doença cardiovascular e os fatores de risco associados, demonstraram que o tor de CLA carne de cordeiros in natura é de $5,6 \mathrm{mg} / \mathrm{g}$ de gordura e que a carne de cordeiros quando comparada a outras espécies demonstra os melhores resultados para o consumo humano.

O conteúdo de CLA na carne depende de dois processos: biohidrogenação ruminal e dessaturação endógena pela enzima $\Delta^{9}$ dessaturase ( BAUMAN et al., 1999). De La Torre et al. (2006) relataram que raça, sexo e idade podem influenciar o conteúdo de CLA nos produtos de ruminantes. Observaram ainda que a taxa de deposição de CLA não depende da quantidade final de gordura corporal dos animais, mas é influenciada por outros fatores, fato que discordou dos resultados do presente experimento, onde os níveis de CLA aumentaram com as espessuras de gordura subcutânea ao abate.

Acredita-se que os ácidos graxos monoinsaturados, como por exemplo, o ácido oleico C18:1n9 trans, não influenciam os níveis de colesterol e que o aumento da concentração do ácido oleico na gordura subcutânea ocorre pelo o aumento da atividade da enzima $\Delta{ }^{9}$ dessaturase. $\mathrm{O}$ aumento na ingestão de ácidos graxos monoinsaturados tal como o ácido oleico é altamente desejável, pois, conforme relatado por Camolas \& Sousa (2010) os ácidos graxos monoinsaturados têm efeito moderado no colesterol plasmático, sendo que o efeito positivo seja a indução a uma melhoria da relação HDL/LDL. Porém, quando em substituição dos saturados, os ácidos graxos monoinsaturados diminuam $\mathrm{O}$ colesterol total, no entanto o efeito hipocolesterolemiante é muito inferior ao dos ácidos gordos polinsaturados (CAMOLAS \& SOUSA 2010).

Kazala et al. (1999) observaram que a deposição no teor médio de C18:1n9, pode estar relacionado à maior atividade da enzima $\Delta^{9}$-dessaturase (18), e na conversão dos ácidos mirístico (C14:0), palmítico (C16:0) e esteárico (C18:0) em seus correspondentes ácidos monoinsaturados (n-9).

Analisando-se a concentração total dos ácidos graxos insaturados, observou-se que as diferentes espessuras de gordura $(2,0 ; 3,0$ e $4,0 \mathrm{~mm})$ influenciaram as concentrações dos ácidos graxos poliinsaturados. Os animais abatidos com $4,0 \mathrm{~mm}$ de espessura de gordura subcutânea apresentaram maior percentual de ácidos graxos poli- 
insaturados, com alta concentração do ácido linoleico (C18:2n-6) e ácido linolênico (C18:3n-3), precursores dos ácidos graxos araquidônico (C20:4n-6) e eicosapentaenoico (EPA, C 20:5n-3). Esses dois ácidos graxos são de extrema relevância, pois se tornam precursores de compostos eicosanoides, os quais apresentam funções fisiológicas e regulatórias importantes (PALMQUIST \& MATTOS, 2011).

As concentrações de EPA (C20:5n-3) e DHA (C22: 6n-3) foram superiores na carne dos cordeiros abatidos com $4 \mathrm{~mm}$ de espessura de gordura subcutânea, o que é desejável devido aos efeitos benéficos desses ácidos graxos a saúde. O EPA e DHA demonstraram altas taxas de bio-hidrogenação ruminal (Scollan et al., 2001), o que explica seus baixos teores de concentração na carne.

A razão de AGPI:AGS, apresentou valor médio de $0,38 \mathrm{~g} / \mathrm{g}$, resultado próximo do reportado por Wood et al. (2003) e recomendado pela Organização Mundial de Saúde, os quais recomendam valor acima de $0,4 \mathrm{~g} / \mathrm{g}$ como ideal, para prevenir doenças associadas ao consumo de alimentos com gordura.

Os valores de $n-3$ apresentaram diferenças significativas para o grupo genético e espessura de gordura subcutânea ao abate, sendo que as maiores médias foram de 2,79 no grupo genético Santa Inês e 2,56 em cordeiros abatidos com 4,0mm de espessura de gordura, demonstrando superioridade aos animais abatidos com 2,0 e 3,0mm de espessura. Sañudo et al. (2000b), avaliando a composição da gordura intramuscular de quatro grupos raciais obtiveram média de 2,99 para $n$ - 3, resultado semelhante ao encontrado no presente trabalho. De acordo com as recomendações nutricionais publicadas pela Organização Mundial de Saúde (2003) as razões $n-6 / n-3$ devem estar entre 4: 1 e 5: 1, que se adequa somente nos cordeiros do grupo genético Santo
Inês e nos cordeiros abatidos com 4,0mm de espessura de gordura subcutânea.

Foram observadas diferenças para os coeficientes de correlação entre a composição química e perfil de ácidos graxos. Observou-se uma correlação perfeita positiva $(p=0,997)$, entre grupo genético e espessura de gordura subcutânea ao abate para o ácido linolênico (C18:3n-3) e o ácido araquidônico (C20:4n-6), (Tabela 4 ).

Os teores de matéria seca apresentaram moderada correlação $\left(-0,30 \leq \rho^{\wedge}<-0,60\right)$; sendo negativa com os ácidos graxos saturados, ácido rumênico $(\mathrm{C} 18 ; 1 \mathrm{n} 9 \mathrm{c} 11 \mathrm{t})$ e oleico (C18:3n-6). E positivamente para os ácidos graxos poli-insaturados linolênico (C18:3n-3) e o ácido araquidônico (C20:4n-6),

Os ácidos graxos saturados correlacionaram-se com os poliinsaturados e ácido linolênico (C18:3n-3), apresentando forte correlação linear negativa $(-0,60 \leq \rho<-0,90)$. Por causarem danos à saúde humana esses resultados são indesejáveis, considerando-se que a concentração plasmática de colesterol é influenciada pela composição de ácidos graxos saturados da dieta (RHEE, 1992). O ácido graxo palmítico (C16:0) aumenta o nível de colesterol sanguíneo e o ácido esteárico (C18:0) não exerce nenhuma influência. Sabendo-se que os ácidos graxos poli-insaturados diminuem os níveis de colesterol sanguíneo, torna-se importante analisar o comportamento destes três ácidos na carne ovina. Wood et al. (2003) reportaram que o Ministério da Saúde do Reino Unido recomenda que a relação AGPI/AGS do perfil lipídico de um alimento deve situar-se acima de 0,4, para evitar doenças associadas ao consumo de gorduras saturadas. 
Tabela 4. Coeficientes de correlação de Pearson entre a composição química e análise de perfil de ácidos graxos de cordeiros Santa Inês e 1/2 Dorper $+1 / 2$ Santa Inês, abatidos com diferentes espessuras de gordura

\begin{tabular}{|c|c|c|c|c|c|c|c|c|c|c|c|c|c|}
\hline & MS & $\mathrm{CZ}$ & PB & $\mathrm{LT}$ & Satu & Mono & Poli & C18:1n9c & C18:2n6t & $\mathrm{C} 18: 3 \mathrm{n} 3$ & C18:3n6 & C50:5n3 & $\mathrm{C} 20: 4 \mathrm{n} 6$ \\
\hline MS & 1 & $-0,223$ & $-0,075$ & $-0,031$ & $-0,338^{*}$ & $-0,282$ & $0,339 *$ & $-0,379 *$ & $-0,042$ & $0,416^{*}$ & $-0,372 *$ & 0,289 & $0,406^{*}$ \\
\hline $\mathrm{CZ}$ & & 1 & 0,142 & $-0,016$ & 0,092 & 0,006 & $-0,051$ & 0,183 & $-0,012$ & $-0,065$ & $-0,162$ & $-0,056$ & $-0,066$ \\
\hline PB & & & 1 & $-0,506^{*}$ & 0,302 & 0,189 & $-0,266$ & 0,203 & 0,132 & $-0,292$ & 0,245 & 0,009 & 0,289 \\
\hline LT & & & & 1 & $-0,176$ & 0,060 & 0,556 & 0,175 & 0,302 & 0,045 & 0,052 & $-0,002$ & 0,042 \\
\hline Satu & & & & & 1 & $0,657 *$ & $-0,899 *$ & 0,144 & 0,0003 & $-0,855^{*}$ & 0,099 & $-0,153$ & $0,860 *$ \\
\hline Mono & & & & & & 1 & $-0,921 *$ & 0,299 & $0,426^{*}$ & $-0,919 *$ & 0,270 & $-0,045$ & $-0,919 *$ \\
\hline Poli & & & & & & & 1 & $-0,248$ & $-0,248$ & 0,976 & $-0,208$ & 0,105 & $0,979 *$ \\
\hline $\mathrm{C} 18 \mathrm{~s} \ln 9 \mathrm{c} 11 \mathrm{t}$ & & & & & & & & 1 & $0,345^{*}$ & $-0,417 *$ & 0,957 & 0,090 & $-0,402 *$ \\
\hline $\mathrm{C} 18: 2 \mathrm{n} 6 \mathrm{t}$ & & & & & & & & & 1 & $-0,298$ & 0,303 & $-0,054$ & 0,286 \\
\hline C18:3n3 & & & & & & & & & & 1 & $-0,389 *$ & 0,080 & $0,997 *$ \\
\hline C18:3n6 & & & & & & & & & & & 1 & $-0,071$ & $-0,367$ \\
\hline C20:5n3 & & & & & & & & & & & & 1 & 0,090 \\
\hline C20:4n6 & & & & & & & & & & & & & 1 \\
\hline
\end{tabular}

*Coeficiente de correlação de Pearson significativo. MS= Matéria Seca; CZ= Cinza; PB=Proteína Bruta; LT= lipídeos Totais; Satu= Saturado; Mono= Monoinsaturado; Poli= Poli-insaturado. 
Entretanto, a relação AGPI/AGS da carne ovina pesquisada, encontra-se bem abaixo da média. No Brasil, não se encontram dados de recomendação quanto à razão AGPI/AGS, porém é recomendável que o total de energia da alimentação fornecido pelas gorduras saturadas seja menor do que $10 \%$, e o teor recomendado de consumo de gorduras do tipo insaturada é de $6 \%$ a $10 \%$ do total de energia diária (BRASIL, 2006).

Os ácidos graxos monoinsaturados demonstraram correlação negativa com os poli-insaturados, ácido linolênico (C18:3n-3) e ácido araquidônico (C20:4n6) e correlação positiva com o ácido linoleico $(\mathrm{C} 18 ; 2 \mathrm{2n}-6)$.

$\mathrm{O}$ ácido rumênico (C18:1n9c11t), correlacionou-se negativamente com o ácido linolênico (C18:3n-3) e com o araquidônico. Nota-se nesta correlação característica desejável, pois o ácido linolênico é bio-hidrogenado a ácido vacênico, posteriormente convertido a CLA, pela enzima SCD nos tecidos (PALMQUIST \& MATTOS, 2011). Sob condições normais de alimentação, a maior parte dos ácidos graxos insaturados ingeridos, linoleico e linolênico é biohidrogenados a $80 \%$.

A carne de cordeiros demonstrou ser altamente benéfica no teor lipídico e de um isômero de CLA. Nas condições de realização do experimento, a carne de cordeiros abatidos com 4,0mm de espessura de gordura subcutânea demonstrou melhor incremento de ácidos graxos poli-insaturados em relação aos demais, melhorando assim a qualidade nutricional da carne tornandoa mais adequada para a alimentação humana.

\section{REFERÊNCIAS}

ASSOCIATION OF OFFICIAL ANALYTICAL CHEMISTS - AOAC. Official methods of analysis. 17. ed. Washington, D.C., 2000.

BARNARD, N.D.; BUSH, A.I., CECCARELLI, A.; COOPER,I.; JAGER, C.A.; ERICKSON, K.I.; FRASER, G.; KESLER, S.; LIVIN, S.M.; LUCEY, B.; MORRIS, M.C.; SQUITTI, R. Dietary and lifestyle guidelines for the prevention of Alzheimer's disease. Neurobiology of Aging, v5, p.74-78, 2014. Suppl. 2.

BAUMAN, D. E., L. H. BAUMGARD, B. A. CORL, and J. M. GRIINARI.

Biosynthesis of conjugated linoleic acid in ruminants. In: AMERICAN SOCIETY OF ANIMAL SCIENCE, 1999, Indianapolis, IN. Proccengins.... Indianapolis, IN: ASAS, 1999 p.1-15

BRASIL. Ministério da Saúde. Secretaria de Atenção à saúde.

Coordenação-Geral da Política de Alimentação e Nutrição. Guia Alimentar para a população brasileira: promovendo a alimentação saudável. Brasília, 2006.

CAMOLAS, J.M.L; SOUSA, J.C. Ingestão de gordura e doença vascular. Conclusões. Revista Fatores de Risco, v.16, p.72-75, 2010.

COSTA, R.G.; BATISTA, A.S.M.; MADRUGA, M.S.; GONZAGA NETO, S.; QUEIROGA, R.C.R.E., ARAUJO FILHO, J.T.; VILLAROEL, A.S. Physical and chemical characterization of lamb meat from different genotypes submitted to diet with different fibre contents. Small

Ruminant Research, v.81, n.1, p.2934, 2009. 
Rev. Bras. Saúde Prod. Anim., Salvador, v.15, n.3, p.740-753 jul./set., 2014 http://www.rbspa.ufba.br ISSN 15199940

COSTA, R.G.; CARTAXO, F.Q.;

SANTOS, N.M.; QUEIROGA,

R.C.R.E. Carne caprina e ovina: composição lipídica e características sensoriais. Revista Brasileira de Saúde e Produção Animal [online], v.9, n.3, p.497-506, 2008.

COSTA, A.G.V.; BRESSAN, J.; SABARENSE, C.M. Acidos graxos trans: Alimentos e efeitos na saúde. Archivos Latinoamericanos de nutrición, v.56, n.1, 2006.

DE LA TORRE, A.; GRUFFAT, D.; DURAND, D. MICOL, D.; PEYRON, A.; SCISLOWSKI,V.; BAUCHART, D. Factors influencing proportion and composition of CLA in beef. Meat Science, v.73, n.2, p.258-268, 2006.

FOLCH, J.; LESS, M.; SLOANE, S.G.H. A simple method for the isolation and purification of total lipids from animal tissues. Journal of Biological Chemistry, v.226, n.1, p.497-509, 1957.

FUNCK, L.G.; BARRERAARELLANO, D. ; BLOCK, J.M. Ácido linoléico conjugado (CLA) e sua relação com a doença cardiovascular e os fatores de risco associados. Arquivos Latinoamericanos de Nutrición, v.56, n.2, 2006.

HASHIMOTO, J.H; ALCALDE, C.R.; SILVA, K.T.; MACEDO, F.A.F.; MEXIA, A.A.; SANTELLO, G.A.; MARTINS, E.N.; MATSUSHITA,M. Características de carcaça e da carne de caprinos Boer x Saanen confinados recebendo rações com casca do grão de soja em substituição ao milho. Revista Brasileira de Zootecnia, v.36, n.1, p.165-173, 2007
INTERNATIONAL ORGANIZATION FOR STANDARDIZATION - ISO. Animal and vegetable fats and oilspreparation of methyl esters of fatty acids: method ISO 5509. Geneva, 1978.

KAZALA, E.C.; LOZEMAN, F.J.; MIR, P.S.; LAROCHE, A.; BAILEY, D.R.; WESELAKE, R.J. Relationship of fatty acid composition to intramuscular fat content in beef from crossbreed Wagyu cattle. Journal of Animal Science, v.77, n.7, p.17171725, 1999.

LEE, K.W.; LIP, G.Y. The role of ômega-3 fatty acids in the secondary prevention of cardiovascular disease. Quarterly Journal of Medicine, v.96, n.7, p. 465-480, 2003.

LIMA, F.E.L.; MENEZES, T.N.; TAVARES, M.O.; SZARFARC, S.C; FISBERG, R.M. Ácidos graxos e doenças cardiovasculares: uma revisão. Revista de Nutrição, v.13, n.2, p.7380, 2000.

MARTIN, C.A.; ALMEIDA, V.V.; RUIZ, M.R.; VISENTAINER, J.E.L.; MATSUSHITA, M.M.; SOUZA, N.E.; VISENTAINER, J.V. Ácidos graxos poliinsaturados ômega-3 e ômega-6: importância e ocorrência em alimentos. Revista de Nutrição de Campinas. v.19, n.6, p.761-770, 2006.

MAHENDRAN, Y.; CEDERBERG, H.; VANGIPURAPU, J.; KANGAS, A.J.; SOININEN, P.; KUUSISTO, J. UUSITUPA, M.; ALA-KORPELA, M.; LAASKO, M. Glycerol and fatty acids in serum predict the development of hyperglycemia and type 2 diabetes in Finnish men. Diabetes Care, v.1, n.36, p.3732-3738, 2013. 
Rev. Bras. Saúde Prod. Anim., Salvador, v.15, n.3, p.740-753 jul./set., 2014 http://www.rbspa.ufba.br ISSN 15199940

MAIA, M.O.; COSTA, F.S., SUSIN, I. et al. Efeito do genótipo sobre a composição química e o perfil de ácidos graxos da carne de borregas. Revista Brasileira de Zootecnia, v.41, n.4, p.986-992, 2012.

MADRUGA, M.S.; ARAÚJO, W.O.; SOUSA, W.H.; CÉZAR, M.F.; GALVÃO, M.S.; CUNHA, M.G.G. Efeito do genótipo e do sexo sobre a composição química e o perfil de ácidos graxos da carne de cordeiros. Revista Brasileira de Zootecnia, v.35, n.4, p.1838-1844, 2006.

MORENO, G.M.B.; BUZZULINI, C.; BORBA, H.; COSTA, A.J.; LIMA, T.M.A.; DOURADO, J.F.B. Efeito do genótipo e do teor de proteína da dieta sobre a qualidade da carne de cordeiros. Revista Brasileira de Saúde Produção Animal [online], v.12, n.3, p.630-640, 2011.

NRC-National Research Council. Nutrient requeriments of small ruminants: sheep, goats, cervids and new world camelids. Washington, D.C.: National Academy Press, 2007.

OLIVÁN, M.; MOCHA, M.J.; MARTINEZ, M.J. Análisis de químico de la carne. In: CAÑEQUE, V.; SAÑUDO, C. Metodologia para el estúdio de la calidad de la canal y de la carne en ruminantes. Madri: INIA, 2000. p.181-203.

OLIVEIRA, D.M.; LADEIRA,M.M.; CHIZZOTTI, M.L. ; MACHADO

NETO, O.R.; RAMOS, E.M.; GONÇALVES, T.M.; BASSI, M.S.; LANNA, D.P.D.; AND RIBEIRO, J.S. Fatty acid profile and qualitative characteristics of meat from zebu steers fed with different oilseeds. Journal Animal Science, v.89, p.2546-2555, 2011.
OSÓRIO, J.C.S \& OSÓRIO, M.T.M. Cadeia produtiva e comercial da carne de ovinos e caprinos - qualidade e importância dos cortes. In: SIMPÓSIO INTERNACIONAL SOBRE OVINOS E CAPRINOS, 2003, João Pessoa. Anais... João Pessoa: EMEPA, 2003. p.403-416.

OSÓRIO, J.C.S.; OSÓRIO, M.T.; OLIVEIRA, N.M.; JARDIM, R.D; PIMENTEL, M.A. Produção de Carne em Cordeiros Cruza Border Leicester com Ovelhas Corriedale e Ideal.

Revista Brasileira de Zootecnia, v.31, n.3, p.1469-1480, 2002. Supl.

PALMQUIST, D.L.; MATTOS, W.R.S. Metabolismo de lipídeos. In: BERCHIELI, T.T.; PIRES, A.V.; OLIVEIRA, S.G. (Ed.). Nutrição de ruminantes. 2. ed. Jaboticabal: Funep, 2011. p.299-322.

PONNAMPALAM, E.N.; SINCLAIR, A.J.; EGAN, A.R.; BLAKELEY, S.J.; LEURY, B.J. Effect of diets containing n-3 fatty acids on muscle long chain n-3 fatty acid content in lambs fed low- and medium- quality roughage diets.

Journal of Animal Science, v.79, n.3, p.698-706, 2001.

RHEE, K.S. Fatty acids in meats and meat products. In: CHOW, C.K. (Ed.). Fatty acids in foods and their health implications. New York: Marcel Dekker, 1992. p.65-93.

ROSANOVA, C.; SILVA SOBRINHO, A.G.; GONZAGA NETO, S. A raça Dorper e sua caracterização produtiva e reprodutiva. Veterinária Notícias, v.11, n.1, p.127 - 135, 2005.

SAINZ, R. D.; HASTING, E. Simulation of the development of adipose tissue in beef cattle. In: MCNAMARA, J. P.; FRANCE, J.; 
Rev. Bras. Saúde Prod. Anim., Salvador, v.15, n.3, p.740-753 jul./set., 2014 http://www.rbspa.ufba.br ISSN 15199940

BEEVER, D. E.(Ed). Modeling nutrient utilization in farm animals. New York: CABI, 2000. p.175-182.

SALDANHA, E.S.P.B.; GONZALES

E. Enriquecimento de ácidos graxos na alimentação de poedeiras . Pesquisa \& Tecnologia, v. 9, n.1, 2012.

SAÑUDO, C.; ENSER, M.E.; CAMPO, M.M.; NUTE, G.R.; MARIA, G.; SIERRA, I.; WOOD, J.D. Fatty acid composition and sensory characteristics of lamb carcasses from Britain and Spain. Meat Science, v.54, n.4, p.339346, 2000a.

SAÑUDO, C.; ALFONSO, M.; SÁNCHEZ, A.; TEIXEIRA, A. Carcass and meat quality in light lambs from different fat classes in the EU carcass classification system. Meat Science, v.56, n.1, p.89-94, 2000b.

SAS Institute. User's guide: statistics. Version 9.1. Cary, 2002.

SCERRA, M.; CAPARRA, P.; FOTI, F.; CILIONE, G.; ZAPPIA, G.; MOTTA, C.; SCERRA, V. Intramuscular fatty acid composition of lambs fed diets containing alternative protein sources. Meat Science, v.87, p.229-233, 2011.

SCHMID, A.; COLLOMB, M.; SIEBER, R.; BEE,G. Conjugated linoleic acid in meat and meat products: A review. Meat Science, v.73, n.1, p.29-41, 2006

SCOLLAN, N.D.; CHOI, N.J.; KURT, E.; FISHER, A.V.; ENSER, M.; WOOD, J.D. Manipulating the fatty acid composition of muscle and adipose tissue in beef cattle. British Journal of Nutrition, v.85, n.1, p.115-124, 2001.
STRYDOM, P.E.; VAN HEERDEN, S.M.; VAN HEERDEN, H.C.; KRUGER, R.; SMITH, MF. The influence of fat score and fat trimming on primal cut composition of South African Lamb. South African Journal of Animal Science, v.39, n.3, p.233242, 2009.

TORNBERG, E. Effects of heat on meat proteins: implications on structure and quality of meat products. Meat Science, v.70, n.3, p.493-508, 2005.

UNDERSANDER, D.; MERTENS, D. R.; THIEX, N. Forage analyses procedures. Omaha: National Forage Testing Association, 1993. 139p.

VALSTA, L.M.; TAPANAINEN, H.; MANNISTO, S. Meat fats in nutrition. Meat Science, v.70, n.1, p.525-530, 2005.

WOOD, J.D.; RICHARDSON, R.J.; NUTE, G.R.; FISHER, A.V.; CAMPO, M.M.; KASAPIDOU, E.; SHEARD, P.R.; ENSER, M. Effects of fatty acids on meat quality: a review. Meat Science, v.66, n.1, p.21-32, 2003.

WORLD HEALTH ORGANIZATION - WHO. Diet, nutrition and the prevention of chronic diseases. Who Technical Report Series, 916. Geneva, Switzerland. 2003.

Data de recebimento: 17/02/2014

Data de aprovação: 23/09/2014 